\title{
Correction to: A tribute and a legacy: Clinical legal education and the bountiful harvest
}

\author{
Richard Grimes $^{1}$
}

Accepted: 22 January 2021 / Published online: 15 February 2021

(c) O.P. Jindal Global University (JGU) 2021

\section{Correction to: Jindal Global Law Review https://doi.org/10.1007/s41020-020-00120-7}

In the original publication of the article, there were certain cross-referencing errors. In footnote numbers 8,11 , and 13 , the cross-reference to footnote number 8 (n 8 ) should be read as a cross-reference to footnote number 7 (n 7 ).

The editors regret these errors.

Publisher's Note Springer Nature remains neutral with regard to jurisdictional claims in published maps and institutional affiliations.

The original article can be found online at https://doi.org/10.1007/s41020-020-00120-7.

* Richard Grimes

richard.grimes@hotmail.co.uk

1 Charles University, Prague, Czech Republic 